\title{
O COMO NAVEGAR ADECUADAMENTE
}

\section{OR HOW TO NAVIGATE PROPERLY}

\section{AUTORES}

Juan José Escribano Otero: Departamento de Programación e Ingeniería del Software. Escuela Superior de Informática. Universidad Europea de Madrid. juan.jose@aol.com

\section{CURRÍCULUM VITAE}

Profesor del Departamento de Sistemas Informáticos de la Universidad Europea de Madrid.

Rosalía Peña: Departamento de Ciencias de la Computación. Universidad de Alcalá rosalia.peña@mixmail.com

\section{CURRÍCULUM VITAE}

Departamento de Ciencias de la Computación. Universidad de Alcalá.

\section{RESUMEN}

Muy frecuentemente se encuentran referencias a la comunidad de usuarios de la red Internet, como mundo virtual, ¿Podemos realmente hablar de un mundo virtual a un entorno en el que muchas personas están trabajando, comprando, cobrando y gastando? El comercio electrónico, el teletrabajo o la telemedicina no son virtuales, son completamente reales. La transmisión de información a través de la red también es real, por supuesto, aunque sea la transmisión de un bien intangible. Sin embargo, las características del medio imprimen unas características especiales al comercio, al 
trabajo, a la atención sanitaria, a la difusión de la información realizados a través de la red, por eso surge el deseo de hablar de otro tipo de mundo, pero el término mundo digital en contraposición de mundo analógico parece mas adecuado que el término mas extendido de mundo virtual frente a mundo real.

\section{PALABRAS CLAVE}

Internet - Seguridad - Navegar adecuadamente - Mundo Digital

\section{ABSTRACT}

Very often there are references to the community of Internet users, such as virtual world, can we really speak of a virtual world environment in which many people are working, buying, collecting and spending? E-commerce, teleworking and telemedicine are not virtual, they are completely real. The transmission of information through the network is also true, of course, even if the transmission of an intangible asset. However, the characteristics of the media print special characteristics to trade, work, health care, dissemination of information carried over the network, so there is the desire to talk about another kind of world, but the term digital versus analog world seems more appropriate than the more standard virtual world versus the real world.

\section{KEY WORDS}

Internet - Security - Browse properly - Digital World

\section{ÍNDICE}

O como navegar adecuadamente 
Normas de etiqueta en el mundo digital

1. Introducción

1.1. Mundo real, Mundo virtual, Mundo digital, Mundo analógico

1.2. Internet como medio de comunicación interpersonal

1.3. Internet como medio de publicación

1.4. Principios humanos permeables de la idiosincrasia de la Red

1.5. Informática como medio de simulación humana

1.6. Internet como elemento vertebrador de una nueva sociedad: la sociedad digital

2. Netiquette

2.1. Normas generales

2.2. Transmisión de información

2.3. Transmisión de conocimientos

2.4. Transmisión de Opiniones

2.5. Transmisión de sentimientos

3. Comunicaciones diferidas

3.1. Correo electrónico y listas de distribución

\subsection{USENET}

3.3. World Wide Web

3.4. FTP y FTP anonymous

4. Comunicaciones en directo

4.1. IRC: Internet Relay Chat

4.2. Transmisión de voz e imágenes. Videoconferencia

5. Valoraciones éticas de conductas y ciberconductas

6. REFERENCIAS BIBLIOGRÁFICAS 


\section{O como navegar adecuadamente}

Merece la pena leer atentamente este artículo, ya que nos permitirá aprender las "buenas formas" del navegador asiduo de Internet.

\section{Normas de etiqueta en el mundo digital}

Juan José Escribano Otero

Departamento de Programación e Ingeniería del Software

Escuela Superior de Informática

Universidad Europea de Madrid

Rosalía Peña

Departamento de Ciencias de la Computación

Universidad de Alcalá

\section{Introducción}

\subsection{Mundo real, Mundo virtual, Mundo digital, Mundo analógico}

Muy frecuentemente se encuentran referencias a la comunidad de usuarios de la red Internet, como mundo virtual, ¿Podemos realmente hablar de un mundo virtual a un entorno en el que muchas personas están trabajando, comprando, cobrando y gastando? El comercio electrónico, el teletrabajo o la telemedicina no son virtuales, son completamente reales. La transmisión de información a través de la red también es real, por supuesto, aunque sea la transmisión de un bien intangible. Sin embargo, las características del medio imprimen unas características especiales al comercio, al trabajo, a la atención sanitaria, a 
la difusión de la información realizados a través de la red, por eso surge el deseo de hablar de otro tipo de mundo, pero el término mundo digital en contraposición de mundo analógico parece mas adecuado que el término mas extendido de mundo virtual frente a mundo real.

\subsection{Internet como medio de comunicación interpersonal}

La Red ha ido evolucionando y en su evolución, ha ido filtrándose en muy diversos órdenes de la "vida social". De origen militar como tantas otras innovaciones tecnológicas, ha ido derivando hacia la sociedad civil sin perder en el proceso ninguno de los espacios conquistados. La última conquista ha sido el gran público, el campo privado. Internet se ha convertido en el medio de comunicación de masas por excelencia, y por proyección de futuro. Cada vez es mayor el número de usuarios que utiliza los servicios que le ofrece la Red como medio de comunicación interpersonal.

\subsection{Internet como medio de publicación}

Junto con esta utilización de Internet en el campo privado, cabe destacar las facilidades y servicios de la Red como medio de publicación. En Internet es fácil publicar un documento, una idea. Y, al menos teóricamente, esa publicación es visible por cualquier internauta del mundo. Internet se convierte, así, en el medio de comunicación a gran escala donde la frontera entre emisor y receptor de una noticia se hace más sutil, más difusa: cualquier lector se puede convertir en cualquier momento en autor. En la Red, el lector de una noticia no sólo recibe el mensaje, sino que junto a él tiene la posibilidad de réplica, de 
comentarla, de ofrecer su punto de vista al resto de los internautas.

\subsection{Principios humanos permeables de la idiosincrasia de la Red}

Esta dicotomía del medio repercute necesariamente en diversos valores bien asentados y definidos en la VA. La intimidad y la imagen pública, la solidaridad o la libertad de expresión son factores que sufren modificaciones cuando los vemos bajo el crisol de la Red. También las pautas de conducta, la buena educación o el principio de autoridad se muestran como elementos permeables de la dinámica de Internet. Sí "todos los medios de comunicación son una reconstrucción" de alguna capacidad biológica, pero acelerada [MCL, 1.993, pág. 94], Internet se manifiesta como un caleidoscopio de capacidades, todas ellas aceleradas vertiginosamente.

El epicentro de toda esta transformación que ya se anuncia lo encontramos en dos factores:

- La intimidad con la que el internauta accede al mundo desde su pantalla, con la consiguiente seguridad que le da el hecho de elegir el ambiente que le rodea.

- La facilidad del internauta por cambiar de personalidad en la red, lo que crea una sensación de control mayor que la experimentada en la VD.

Y es que, gracias a la simulación, la modelización y la realidad digital, el ordenador ha objetivado también la imaginación. El hipotético ... y si ... ya no es una especulación. Basta con cambiar los parámetros de un modelo simulado por ordenador (modelo de, por ejemplo, una 
conducta social) y sabremos en poco tiempo las consecuencias de la suposición inicial. El ordenador se ha convertido en el interfaz de la imaginación.

\subsection{Informática como medio de simulación humana}

En la búsqueda de conocimientos sobre sí mismos, los seres humanos han recurrido desde siempre a imágenes reflejadas. La mitología o los cuentos para niños, esas creaciones en apariencia tan simples, pero en las que se muestran las verdades más profundas, nos lo enseñan: Narciso no fue tal hasta que reconoció su rostro en las aguas claras de una fuente; el espejito mágico hizo de la cruel madrastra de Blanca Nieves una mujer más sabia, al confesarle que no era la más bella. Desgraciadamente no hay un espejo para el hombre. No hay otro como él, salvo él; y por eso el autoconocimiento es una quimera.

En este afán de conocimientos -y en el deseo de emular a las divinidadesestá el origen del mito del autómata. El hombre ha creado en la imaginación y ha intentado crear en la realidad seres que, sin ser él, son como él. Seres salidos de manos humanas que se mueven por propios intereses y que disfrutan de un simulacro de vida. El Golem hebreo, Pinocho, los robots de Asimov, HAL 9000, son ejemplos, a diversos niveles, del arraigo de este mito.

Los sabios ilustrados del siglo XVIII confiaban en alumbrar la vida basándola en engranajes y poleas y en el convencimiento de que el mundo y la existencia no son sino un complejo mecanismo de relojería. Kempelen (1734-1804) y sus autómatas, uno jugador de ajedrez y otro parlante (Mechanismus der menschlicher Sprache, Viena, 1.791); La 
Mettrie (1.709-1754), teórico y constructor de un hombre-máquina (L'homme machine, 1.747); Vaucanson (1.709-1782), inventor de ingenios de tipo robot y constructor en 1.738 de un Flautista mecánico y el 1.739 de un Tamborilero mecánico, son claros ejemplos de ello.

Unas décadas más tarde, Mary Shelley elucubró con la creación de vida gracias a un elemento más sutil, y por entonces gran desconocido, la electricidad. Por eso el monstruo de Frankestein llegaba a la vida impulsado por el chispazo de un rayo y la locura de su creador. En definitiva, no pasa mucho tiempo desde la aparición de un nuevo modelo explicativo del funcionamiento del mundo, hasta que a alguien se le ocurra la posibilidad de creación de un hombre artificial basado en ese modelo. Por eso, no es de extrañar que el mito haya renacido con ímpetu en nuestro siglo a partir de las ideas y trabajos de unos neopitagóricos reduccionistas (Turing, Shannon, Von Newman, McCarthy, Minsky,...). El hombre empieza a mirarse en el espejo binario y espera poder aprender algo de sí mismo en el reflejo.

\subsection{Internet como elemento vertebrador de una nueva sociedad: la sociedad digital}

Al conectar ordenadores mediante una red mundial como Internet, se crea una nueva sociología. Las relaciones se establecen en una sociedad digital, una sociedad en la que el individuo es por primera vez responsable casi por completo de sí mismo. No importa la raza, la apariencia física o el sexo a la hora de participar en una comunidad digital. Y no importa porque el individuo puede adoptar cualquier "parámetro". Philip Pullman, en su novela Luces del Norte, dibuja una sociedad donde cada humano va acompañado de un ser mitológico al 
que llama daimonion que viene a ser una representación externa del estado de ánimo interior de su propietario. Pues bien, de alguna manera, el que participa en la sociedad digital es el daimonion del usuario, teledirigido por su dueño. Y, como en el libro ocurre con los daimonion de los niños, el internauta puede hacerle cambiar de forma a voluntad.

Esta sociedad digital que nace prácticamente por generación espontánea y sin órganos de control, va a medida que crece, inventando o readaptando según los casos, pautas de conducta que permitan una buena convivencia entre internautas. La necesidad de estos códigos se fundamenta en dos características de esta sociedad digital:

- Su universalidad, por la que las referencias culturales propias del origen geográfico de cada internauta no pueden extrapolarse directamente a la Red

- Su forma de transmitir información es fundamentalmente mediante texto escrito, lo que condiciona la transmisión de información en general, y muy particularmente, la transmisión de sentimientos y estados de ánimo

El conocimiento y estudio de estas pautas no solo es interesante para los internautas, ya que, en virtud de la expansión ya comentada en este documento, es posible que se conviertan en pautas comunes en multitud de actividades humanas, aún no relacionadas con las telecomunicaciones. Actividades tan fuertemente socializadoras como el trabajo, podrán cambiar si el ancho de banda aumenta espectacularmente. $Y$ ese aumento en la capacidad de comunicación es un caballo de batalla que empieza a dar sus frutos. También las relaciones políticas sufrirán una profunda transformación: ¿podrá mantenerse la democracia representativa - 
sistema ideado en el siglo XVIII, una época donde no había correo ni infraestructura vial digna de tal nombre - en un mundo donde la gente tenga acceso inmediato y de primera mano a los datos y dossieres de los temas más candentes; donde pueda expresar su opinión sin necesidad de intermediarios; donde, al contrario de lo que ocurre en la actualidad, sea receptor discriminativo de información y, más importante, emisor de dicha información, sin tener que adquirir para ello una emisora de televisión; donde los ciudadanos puedan agruparse según sus intereses de una forma libre y altamente participativa, como ya ocurre en los foros de discusión de Internet?

La Red se comporta como un gas que se expande para abarcarlo todo. Las posibilidades que ofrecen para la comunicación y las relaciones sociales dan vértigo y la forma en que el ciudadano del siglo XXI utilice Internet determinará la estructura social de la humanidad. Algunos factores de esta sociedad ya están presentes en la Red, por lo que se puede pronosticar el desarrollo futuro. Nubes digitales anuncian lluvias en la sociedad que transformarán su jerarquía actual. Conviene echar un vistazo a la sociedad digital para intentar acercarnos desde allí a la construcción del futuro.

\section{Click, :-)}

\section{Netiquette}

Con este término se conoce el conjunto de normas, procedimientos y recomendaciones encaminadas a facilitar la fluidez de las comunicaciones interpersonales en la sociedad digital. Es un código ético y estético oficioso que todo internauta que se precie conoce. Su naturaleza oficiosa permite la aparición 
de multitud de excepciones y matizaciones sin que por ello se considere necesariamente un maleducado al transgresor. Esta netiquette, si bien etimológicamente significa etiqueta en la red, se distingue de las normas protocolarias de la sociedad analógica en su flexibilidad. El principio básico de toda interpretación ética en Internet debe ser la intención y, de hecho, muchas de las normas de conducta van encaminadas a facilitar la transmisión de las intenciones del internauta.

\subsection{Normas generales}

Dependiendo de la naturaleza de la comunicación, del medio elegido para llevarla a cabo de entre los posibles servicios que brinda la Red y del auditorio al que vaya dirigida, deberemos adoptar unas pautas u otras. Pero hay algunos principios fundamentales que subyacen tras la mayoría de las recomendaciones.

Algunos de dichos principios, nacen de la situación contractual de las telecomunicaciones, mientras que otros pretenden soslayar diferencias culturales entre internautas.

Básicamente, este código se apoya en los siguientes postulados:

\section{- Procura no ofender a nadie}

O mejor dicho, procura no ofender a nadie "sin querer". Al utilizar fundamentalmente la escritura como medio de comunicación, a menudo sin el apoyo de información visual ni sonora, la posibilidad de un malentendido aumenta considerablemente, sobre todo si la comunicación va dirigida a un auditorio amplio, 
variopinto y posiblemente internacional. Buena parte del esfuerzo en la confección de este código digital pretende minimizar la aparición de estas malas interpretaciones. En algunos servicios existe la posibilidad de réplica (IRC, USENET, listas de distribución...) bien en directo o en diferido, pero no conviene confiar demasiado en que un internauta ofendido por un comunicado se moleste en pedir explicaciones, dando la oportunidad de hacer aclaraciones. Conviene prevenir.

\section{- Se conciso}

No hay que olvidar que muchos internautas actualmente pagan por el tiempo que dura la conexión. Esta característica cambiará cuando se establezca algún tipo de tarifa plana de acceso, pero mientras tanto, conviene hacer un esfuerzo por concretar las comunicaciones a niveles previsibles por el receptor o receptores de la misma. Desde luego, no será lo mismo publicar un artículo en un grupo de discusión filosófica o poética, que comunicar una noticia a un viejo amigo, pero, en ambos casos, conviene ajustarse a lo que el auditorio puede esperar de ese documento.

Esta concisión debe regir también la decisión de donde publicar (o comunicar, dos palabras que en la Red, la mayoría de las veces, se comportan como sinónimos) un documento. Seguro que podremos encontrar un lugar cuyo auditorio concuerde exactamente con los contenidos que queremos divulgar, por lo que resulta muy conveniente buscarlo. Si por alguna extraña razón ese lugar no existe, podemos crearlo. Esta posibilidad de crear nuevos grupos supone uno de los atractivos añadidos de la Red. 


\subsection{Transmisión de información}

El contenido de nuestra comunicación también influirá en las pautas a seguir para una correcta publicación en Internet. Dependiendo de lo que se transmita y, sobre todo, del nivel de implicación personal que se vaya a especificar entre el transmisor y lo transmitido, habrá que aplicar distintas normas y recomendaciones.

\subsection{Transmisión de conocimientos}

Si el documento expresa información objetiva sobre cualquier tema, sin ninguna implicación personal del emisor, su redacción seguirá las mismas normas que para una publicación digital. Dependiendo del auditorio al que vaya dirigido, el tono del documento podrá ser desenfadado o más formal.

Conviene destacar que, si es posible que haya alguien que quiera replicar al documento, bien por discrepancias con alguna parte de su contenido, bien por que sean posibles comentarios de apoyo o repulsa, bien por cualquier otro motivo, será necesario incluir un mecanismo para que lo haga. Este mecanismo suele traducirse en un enlace a la dirección de correo del autor o del editor cuando el documento aparece en la World Wide Web o USENET. En servicios como el IRC o las listas de distribución, esa posibilidad de réplica forma parte de las características del propio servicio, con lo que será redundante facilitarla.

\subsection{Transmisión de Opiniones}


Cuando lo comunicado es o incluye una opinión personal o de grupo sobre un tema, conviene extremar las precauciones. En primer lugar, conviene empezar el documento dejando muy claro que lo que contiene es una opinión sobre algo y no una verdad objetiva. Para ello, se suelen usar expresiones claras al respecto o, aún mas "educado", abreviaturas, como por ejemplo IMHO (In My Humble Opinion, en mi modesta opinión) que no ocupan mucho sitio en el mensaje y dejan claro el carácter subjetivo del mismo. El empleo de siglas y abreviaturas esta muy extendido en la Red porque encaja perfectamente con el segundo postulado general mencionado antes, la concisión.

Cuando la opinión vertida en la comunicación versa sobre una noticia o similar, conviene incluir en el propio mensaje el contenido de la misma o al menos un extracto de ella, para que el lector disponga del hecho objetivo sobre el que se opina junto con la opinión. Esta práctica, además de evitar malos entendidos, ayuda también al autor a ceñirse a la noticia en su crítica.

$\mathrm{Ni}$ que decir tiene que la posibilidad de réplica debe formar parte del documento sin excusa posible. Además, conviene elegir correctamente el lugar de publicación de las opiniones, sobre todo si van dirigidas a un grupo numeroso. Si el documento se va a publicar en una lista de distribución o en USENET, conviene asegurarse de que su contenido será de interés para los lectores de la lista o del grupo elegido. De nuevo, si dicho grupo no existe, tendremos la posibilidad de crearlo.

\subsection{Transmisión de sentimientos}


A menudo -sobre todo cuando el documento contiene opiniones - el autor quiere dejar claro que algún aspecto del mensaje le provoca alguna reacción sentimental o que tal o cual frase la escribe en un determinado estado de ánimo. Otras veces, sobre todo en comunicaciones interactivas, pretende dar pistas a sus interlocutores sobre algún aspecto físico o visual. La transmisión de este tipo de información no verbal, enriquece, humaniza y a menudo evita errores de interpretación.

Las piezas más utilizadas para comunicar estos aspectos se denominan emoticones. Son representaciones de partes del cuerpo (generalmente la cara) esbozadas con el teclado. Para comprender un emoticón, hay que girar el dibujo noventa grados y mirarlo con un poco de imaginación. Además, el contexto en el que aparecen suele ayudar a descifrarlos. Existen, literalmente, cientos de emoticones distintos y cada día aparecen nuevos. Lo que nació como una necesidad para enriquecer la comunicación se ha convertido en un divertido juego de habilidad.

El más socorrido, y posiblemente el más antiguo de todos, es el emoticón que manifiesta que el autor esta contento, bien por algo que ha leído o por algo que ha escrito. El dibujo es :-) donde los dos puntos representan los ojos, el guión la nariz y el paréntesis una boca sonriente. Este emoticón, llamado en inglés smile, es el causante de que muchos autores llamen a estas "caritas", incorrectamente, smiles. Nótese la sencillez del dibujo que solo usa tres caracteres presentes en cualquier teclado. La inmensa mayoría de los emoticones cumplirán ese prerrequisito: deben usar caracteres presentes en el teclado. Pues bien, a pesar de usar solo tres símbolos (y transmitir con ellos un sentimiento difícilmente "redactable" por otro medio) a menudo se suprime la nariz en el dibujo y se convierte en :). Este ahorro del guión se justifica en la poca carga 
informativa de la nariz. Otra variación suele ser :o) que representa una cara sonriente de nariz gorda...

En la siguiente tabla podrá encontrar un conjunto básico de emoticones. Hacer una lista exhaustiva de los mismos sería una labor ímproba y con fecha de caducidad demasiado corta: aún hay quien tiene mucho tiempo libre para divertirse, ;-)

\section{Emoticones Básicos}

\begin{tabular}{|c|c|}
\hline Emoticón & Significado \\
\hline$(-) \quad:) \quad: 0)$ & Alegría \\
\hline$:-(\quad:): 0($ & Tristeza \\
\hline$\left.i^{-} \quad ;\right)$ & $\begin{array}{c}\text { Comentario pícaro. Guiño de un } \\
\text { ojo. Complicidad }\end{array}$ \\
\hline$:^{\prime}-\left(\quad:{ }^{\prime}(\quad: \sim(\right.$ & Llorar \\
\hline$:-D \quad: D$ & Carcajada \\
\hline$X-D \quad X D$ & Muriéndose de risa \\
\hline$:-b \quad:-p \quad: b \quad: p \quad:-p \quad: p$ & Sacar la lengua \\
\hline$\left.:-)^{\prime} \quad:\right)^{\prime}$ & Caerse la baba \\
\hline$:-0 \quad: 0 \quad:-0 \quad: 0$ & Sorpresa \\
\hline$:-/ \quad: /$ & Mueca, suele ser de desagrado \\
\hline$\}:-1$ & Frunciendo el entrecejo \\
\hline$:-? \quad: ?$ & Duda, "no comprendo" \\
\hline$:-\mathrm{X} \quad:-\mathrm{E}$ & Enfado y mucho enfado \\
\hline :-* & Un beso \\
\hline B-) & Llevo gafas \\
\hline$:-Q$ & Soy fumador \\
\hline 8-) & Sonrisa de asombro \\
\hline
\end{tabular}


Observación: A menudo se repite el carácter mas significativo del emoticón para expresar más intensidad. Así, encontramos :-))))))) cuando la alegría es grande o :--******* cuando el beso es "muy sentido" o apasionado. En principio, mayor número de repeticiones indica mayor intensidad, pero en la práctica nadie cuenta los paréntesis o asteriscos.

\section{Comunicaciones diferidas}

Los servicios que Internet ofrece para las comunicaciones interpersonales, se clasifican en dos familias: aquellos donde emisor y receptor se encuentran a la vez presentes y los que no es necesaria la coincidencia en el tiempo. Como es natural, las reglas y recomendaciones en ambos tipos de servicios se ven afectadas por esta propiedad.

\subsection{Correo electrónico y listas de distribución}

El correo electrónico es posiblemente el servicio más usado de Internet. Permite la comunicación entre personas con mayor rapidez que el correo postal pero con su misma versatilidad. Las normas de conducta que rigen los mensajes de correo son muy laxas, debido fundamentalmente a la variedad de mensajes. El correo electrónico es otra forma de correo, por lo que las normas utilizadas para escribir una carta suelen seguir vigentes en la Red, con algunas matizaciones. Cabe destacar:

- Evite tratamientos excesivamente formales, sobre todo cuando el mensaje vaya dirigido a personas de otras culturas y/o lenguas. En la Red se suele permitir un lenguaje más desenfadado 
- Firme sus mensajes

- Sea tan conciso como pueda

- Ordene alfabéticamente las direcciones cuando sean múltiples

- Cuando adjunte ficheros, procure que sean pequeños.

Si el fichero es grande, deberá comprimirlo

- Nada de virus. Usted es responsable de los mensajes que manda

- No conteste mensajes ofensivos. Cuidado con el "correo basura"

- Cuando conteste a un mensaje, incluya sólo la parte del texto original relevante

Las listas de distribución son conjuntos de direcciones de correo de gente interesada en un mismo tema. Cuando alguien se suscribe a una lista de correo sobre un tema específico, empezará a recibir en su buzón todos los mensajes que cada uno de los miembros de dicha lista envíe a la misma. La propia lista se manifiesta como una dirección de correo que redirige los mensajes que le mandan a todos los miembros. Suscribirse a varias listas de distribución permite estar en contacto con gente interesada en temas comunes. Muchos profesionales de todos los campos utilizan las listas de distribución como fuente de soluciones a sus problemas y como foros de discusión donde volcar opiniones y comentarlas.

El principal problema de las listas de distribución estriba en el volumen de mensajes que pueden generar. Existen listas en las que se producen decenas diarias de mensajes que llegan al buzón de cada miembro 
obligándoles a utilizar mucho tiempo para leerlos. Este suele ser el motivo de abandono de la mayoría de las listas. De hecho, suele producirse un movimiento pendular entre los internautas: cuando descubren la posibilidad de suscribirse a listas de distribución, se dan de alta en multitud de ellas, dándose cuenta en breve que son incapaces de absorber el aluvión de mensajes que llegan a su buzón. Entonces, se borran de todas o de la mayoría, lo que suele provocar cierta angustia del tipo "y si al borrarme de esta lista me pierdo lo más interesante de la Red". Así pues, la primera recomendación es esta: asegúrese de querer suscribirse a una lista antes de hacerlo.

Las normas de conducta en este tipo de servicios más destacadas y aceptadas son:

- Antes de mandar mensajes a una nueva lista, lea las FAQ (Frecently Ask Questions)

- Conviene además que dedique una semana o dos a leer los mensajes de la lista antes de mandar los suyos. Esto le permitirá conocer la "cultura del grupo"

- Comunique a la lista sólo mensajes de su interés. Evite los "OFFTOPPICS" y no conteste a los ajenos

- Sea conciso y evite mensajes que pudieran ser ofensivos para alguien del grupo

- Conteste en público sólo cuando sea necesario, frecuentemente es suficiente contestar al autor del mensaje 
- La publicidad y los mensajes comerciales no son bien recibidos

- Envíe mensajes de Resumen cuando le hayan contestado a preguntas que pudieran ser interesantes para más miembros del grupo

- Elija con cuidado el asunto "subject " de sus mensajes. Debe ser claro

- Dado que quien reciba un mensaje puede ser miembro de varias listas, es adecuado que delante del asunto ponga un identificativo de la lista a la que pertenece. Por ejemplo [CE] para la lista de Computer ethic.

\subsection{USENET}

USENET es una de las redes que forman Internet. Los documentos que allí se encuentran reciben el nombre de noticias, artículos o news que se organizan en grupos o Foros de discusión. Estos foros de discusión, a su vez, se jerarquizan en forma de árbol para facilitar la comprensión de su contenido. Por ejemplo, la categoría soc engloba temas sociales, culturales y religiosos, comp representa temas de informática, sci investigación científica, alt representa temas "alternativos" y bajo este afijo encontramos grupos variopintos y desenfadados sobre casi cualquier tema [ESE, 1.996]. Dentro de cada una de estas categorías, se encierran a su vez nuevas divisiones. Por ejemplo, el grupo comp.graphics.animation está dedicado a animaciones por ordenador. 
Existen grupos de noticias moderados y grupos sin moderador. La figura del moderador se justifica para mantener el foro libre de artículos que se aparten del interés de la lista. Cuando un grupo es moderado, los artículos a publicar se mandan al moderador y éste lo enviará (si lo considera oportuno) al grupo. En cambio, en los grupos sin moderador, los artículos se mandan directamente al foro de discusión sin más trámites.

En general, todas las normas de conducta comentadas para las listas de distribución, siguen siendo válidas para los grupos de discusión de USENET y equivalentes. De hecho, mucha gente confunde ambos términos. La diferencia básica entre una lista de distribución y un Foro es, desde el punto de vista del usuario, que los artículos de las listas de distribución llegan al buzón del suscriptor sin intervención por su parte, mientras que para leer los publicados en las News el internauta deberá conectar expresamente con su servidor de ese Foro. Técnicamente, las diferencias son más patentes ya que las primeras utilizan como medio de difusión el correo electrónico (y el protocolo SMTP) mientras que los segundos necesitan de un servidor de News y utilizan el protocolo NNTP.

Recomendaciones de conducta propias de este servicio podrían ser:

- Siga todas las normas expresadas en el apartado "Listas de distribución"

- Evite el spam (IMPORTANTISIMO), tanto el voluntario como el involuntario. Con este término se conoce a la propagación excesiva de mensajes a distintos grupos de noticias 
- Cuando vaya a contestar a un artículo que le parece inapropiado (ofensivo o fuera de lugar), asegúrese de no estar favoreciendo con ello una discusión fuera de contexto. Algunas personas "cibermaleducadas" mandan a propósito mensajes inapropiados para crear polémica y reventar un grupo de discusión.

- Sea paciente y no se precipite en contestar. Recuerde que la propagación de News no es inmediata ni homogénea.

\subsection{World Wide Web}

Este es, sin duda, el servicio de más éxito y de mayor crecimiento de todos los que brinda Internet. Consiste en la publicación de documentos hipertextuales, es decir, documentos que incluyen enlaces a otros documentos relacionados y posiblemente en distintas partes del mundo. Se puede comprender su éxito, teniendo en cuenta que:

- No está patentado, lo que hace de la Web un sistema de publicación abierto

- La facilidad y transparencia con que el lector navega entre distintos documentos y servidores

- La posibilidad de incluir gráficos, sonidos, animaciones junto con el texto, haciendo los documentos Web mas atractivos.

La utilización de la Web como medio de publicación de información general y "seria" es conocida, pero también existen documentos web que sirven como medio de comunicación personal. De hecho, el número de páginas personales crece vertiginosamente y cada vez más grupos de 
interés crean sus propios documentos como medio de publicación de sus ideas. 
A la hora de crear este tipo de documentos hay que tener en cuenta:

- Facilite un medio para que el lector se ponga en contacto con el autor

- Elija el tono adecuado al hipotético lector

- Cuide el tamaño de su página, recuerde que el lector paga por el tiempo de conexión

- Incluya en el código de la página información suficiente para identificar al autor o grupo de autores

- Facilite la lectura eligiendo correctamente los elementos empleados, especialmente los colores y la imagen de fondo de sus páginas. Recuerde que publica en la Web para "contar algo" a alguien. De nada sirve un diseño espectacular que no permita leer el texto.

- Diseñe con cuidado la estructura de su documento. Facilite la navegación entre los distintos nodos. Si obliga al lector a pasar por la homepage para cambiar de sección, le está obligando a permanecer demasiado tiempo intercambiando nodos

- Cuide la ortografía y la redacción de su documento 


\subsection{FTP y FTP anonymous}

El servicio FTP (File Transfer Protocol) permite recuperar ("bajar") o enviar ("subir") archivos desde algunos servidores de Internet. Cuando este servicio se consigue gracias a un nombre de usuario y una contraseña, es porque ese internauta tiene cuenta en ese servidor, o lo que es lo mismo, derechos de acceso a esa información. Pero existen multitud de archivos accesibles vía Internet sin necesidad de declarar nuestra identidad. Este tipo de servicio se llama FTP anonymous (anónimo).

Cuando el acceso es a una cuenta propia, se puede considerar (al menos, a efectos éticos) como si el internauta estuviera accediendo a su disco duro local. La única regla de conducta que cabe subrayar es procurar no consumir excesivos recursos del servidor para no perjudicar a los demás usuarios del mismo. No obstante, es corriente que el administrador de la máquina haya puesto ya limitaciones a cada usuario.

Cuando el acceso es anónimo las normas y recomendaciones a tener en cuenta son:

- Respete escrupulosamente las normas propuestas por el servidor, si es que las hay

- No utilice dichos servidores para guardar información que pudiera ser ofensiva para algún internauta 
- Responda a la pregunta sobre la password con la dirección de correo electrónico propia. Esto dejará claro nuestra buena intención, al identificarnos.

\section{Comunicaciones en directo}

El segundo grupo de servicios (y posiblemente el más interesante desde el punto de vista de las relaciones sociales) se basa el la posibilidad de charlar vía Internet. El más extendido de estos servicios es el IRC (Internet Relay Chat) que permite a un internauta charlar en tiempo real y mediante texto escrito con otros internautas.

\subsection{IRC: Internet Relay Chat}

Un internauta que desee charlar con otros en el IRC necesitará un cliente de IRC (existen varios gratuitos, como el programa MIRC o el PIRCH, ambos fácilmente localizables en la Red) y el nombre de un servidor de IRC. Dichos servidores se conectan formando redes de IRC. Un internauta conectado a un servidor de IRC de la red undernet, por ejemplo, podrá hablar con cualquier otro internauta que se encuentre conectado a cualquier servidor de la misma red undernet.

Dentro de cada red de IRC los internautas se agrupan en "canales". Existen canales de casi cualquier tema y un sinfín de canales sin tema específico. Además, cualquier internauta podrá crear un canal y esperar a que otras personas decidan entrar en él para "chatear" con ellos. El nombre de un canal es una almohadilla, \#, seguida de una palabra sin espacios en blanco. Para aclarar el contenido del canal (si fuera necesario) se puede incluir un comentario o topic apropiado. Dicho topic podrá cambiarse a voluntad por los miembros autorizados de dicho canal. 
Cada internauta conectado a una red de IRC se identifica ante sus interlocutores con un apodo, llamado nickname o nick. Así pues, en un momento determinado, no puede haber dos internautas con el mismo nick en una misma red de IRC.

Si un internauta entra en un canal llamado, por ejemplo, \#atico, los demás internautas allí reunidos verán como aparece en sus pantallas el nuevo nick. Cuando un internauta entra en un canal, aparecerán en su pantalla todos los textos que los demás compañeros de canal escriban desde sus teclados y podrá mandar mensajes al canal que aparecerán en las pantallas de todos los miembros.

Eventualmente, un internauta puede querer establecer una comunicación privada con un nick concreto. Para ello, creará un canal privado para ambos utilizando dos posibles comandos de IRC: /QUERY y /DCC CHAT. Ambos abren una nueva ventana donde aparecerán los mensajes del interlocutor junto con los propios y nadie mas que ellos dos verán dichos mensajes. El hecho de abrir un "privado" con un nick se puede compaginar (con un poquito de práctica) con la permanencia en un canal (o en más de uno), permitiendo así al internauta mantener una conversación privada y una pública a la vez.

Además de posibilitar la comunicación en directo con otras personas, el IRC permite mandar archivos a un nickname concreto mediante el comando /DCC SEND. Existen otros muchos comandos encaminados a mejorar las posibilidades de comunicación entre internautas o para intentar descubrir alguna pista sobre el estado actual de la conexión de un nick concreto o la identidad que se esconde tras del apodo. El 
comando básico para esto último es /WHOIS y en la mayoría de los casos no nos da pistas fiables sobre la identidad del internauta.

Es en este servicio donde más escrupulosamente se deben seguir las reglas de cortesía, ya que se está hablando "a la cara" en directo y en público. Como recomendaciones al respecto cabe destacar:

- No mande archivos ofensivos o dañinos por /DCC SEND

- No mande mensajes generales a toda la red de IRC, aunque es técnicamente posible (y muy fácil), este tipo de mensaje saturan el servicio y perjudica a todos los internautas.

- Los mensajes publicitarios no son bien recibidos, salvo que se produzcan como respuesta a una petición o en canales expresamente dedicados a ello

- No facilite en un canal datos personales de otro internauta. Se considera "dato personal" hasta el nombre de pila.

- Salude a todos los participantes al entrar o salir de un canal

- Sea paciente si no se obtiene una respuesta inmediata al mandar un mensaje a un canal. A menudo existe un retraso (denominado LAG) desde que se manda un mensaje hasta que aparece en las pantallas de los contertulios. Enviar repetidamente un mensaje a un canal (acción que recibe el nombre de Flood) puede interferir en la fluidez del mismo 
- Respete el tema en los canales temáticos. Si el tipo de conversación de un canal no es de nuestro agrado, se debe saludar a los participantes y abandonarlo

- Elija el tono de los mensajes. Existen canales, como \#insultos, donde esta permitido el empleo de un lenguaje soez, pero no es lo habitual

- Sea conciso y ameno, dentro de lo posible

- El nickname elegido debe ser fácil de escribir, sin acentos ni caracteres especiales

\subsection{Transmisión de voz e imágenes. Videoconferencia}

Además de la transmisión de texto, es posible transmitir voz vía Internet y hasta vídeo, gracias a sistemas de videoconferencias. A medida que el ancho de banda (cantidad de información por unidad de tiempo que una línea de comunicaciones es capaz de transmitir) vaya aumentando, estos servicios se popularizarán en el ámbito personal, pero, de momento, son pocos los usuarios que se pueden permitir su utilización con aceptables resultados.

No obstante, en sesiones de videoconferencias "caseras", conviene, sobre todo, ser pacientes, hablar pausadamente y evitar los movimientos bruscos que sorprendan al interlocutor.

\section{Valoraciones éticas de conductas y ciberconductas}


La misma existencia de un código ético propio para Internet habla de la continua transgresión de sus normas. Además, existen comportamientos reprochables en la vida real que mantienen su valoración ética (y a menudo penal) en la Red. No obstante, también encontramos conductas que cambian de valoración dentro y fuera de Internet.

Existen comportamientos que sólo pueden realizarse en las comunicaciones electrónicas, otras en cambio, son reflejo exacto de conductas reales.

Entre las primeras conviene destacar el comportamiento propio de dos "tribus" cibernéticas: los hackers y los crackers. La definición del término hacker no resulta fácil como se puede apreciar en [TRE, 1996, pags. 138,139], aunque la descripción más usual es "experto informático que viola la privacidad de ordenadores y documentos en redes de ordenadores, por el placer de demostrar su pericia". Estos hackers suelen dejar una marca en los sistemas en que entran sin permiso. Además, sólo tiene "valor" para la cultura hacker entrar en ordenadores que se consideran especialmente protegidos, como organismos gubernamentales, bancos o grandes empresas.

Como los objetivos de los hackers rara vez son ordenadores personales, los internautas no condenan estas prácticas con convicción. Es más, a menudo ante las detenciones de hackers, suelen levantar discusiones a favor de su puesta en libertad. Es decir, los hackers convictos y confesos reciben de la sociedad analógica trato de criminales, mientras que la cibersociedad suele tratarlos como héroes. En el trasfondo se encuentra la idea romántica de Robin Hood, no porque los hackers repartan riquezas entre los ciberpobres, sino porque al saltarse las protecciones desarrolladas por grandes compañías con muchos recursos, recuerdan a todos la posibilidad de igualar en destreza a los grandes gurús, pero con bajo presupuesto. Es, una vez más, la historia de David contra Goliat. 
Los crackers en cambio, se definen como "expertos en informática que violan protecciones de archivos y programas con ánimo de lucro". Estos crackers consiguen reventar las cerraduras informáticas con las que los programadores protegen su trabajo para luego vender copias de los mismos muy por debajo de su valor de mercado.

Por supuesto, está perseguido por la ley, pero es raro el internauta que no utilice más de uno de estos programas "crackeados" en su ordenador. De hecho, el asunto se parece al problema con el que se enfrenta la sociedad de autores en otros órdenes, como las fotocopias ilegales de libros, copias de videocasettes y copias musicales. En todos estos casos, la costumbre no ayuda a la aplicación de la ley. En el caso particular de programas informáticos y documentos electrónicos, se añade el agravante de la facilidad y rapidez de la producción de copias una vez construido el "crack" y la facilidad y universalidad de la distribución de las mismas. La sociedad internauta parece hacer la vista gorda ante estos temas.

Bajo esta laxitud (que contrasta con la dureza con la que se castiga, por ejemplo, el envío de publicidad a una lista de distribución, motivo de al menos un vacío social de los demás suscriptores, si no de la expulsión) descansa la dejadez con la que el internauta se enfrenta al principio de propiedad.

En Internet hay distintos niveles de propiedad de programas e información y la propiedad completa no está muy representada. Proliferan multitud de palabras con el sufijo inglés -ware que intentan explicar las reglas de uso de un determinado archivo, muchas de ellas difícilmente monitorizables por terceras personas y que, por lo tanto, suelen dejar a los buenos principios éticos del internauta su correcta utilización. Freeware y Shareware son los dos términos más utilizados. 
Freeware: indica que un archivo es de uso libre sin restricciones

Shareware: advierte que el uso del archivo está sujeto a reglas concretas impuestas por el propietario. Estas reglas suelen ser de los siguientes tipos:

- Uso libre siempre que sea con carácter personal. Si se va a usar profesionalmente, se debe mandar una cantidad de dinero al creador. Será el internauta que reciba dicho archivo shareware el que determine si va a usarlo personal o profesionalmente

- Uso libre durante un periodo determinado de tiempo o para un número determinado de usos. Después de agotado el periodo de prueba, el usuario decidirá borrarlo o registrarse para seguir utilizando el programa de manera legal .

Puede apreciarse la confianza de la cibersociedad en (que en la Red se encuentra ante las buenas conductas éticas) ética de sus usuarios, haciendo caer sobre ellos el control de la propiedad. Bien es verdad que, a juzgar por la consideración que a este principio le dedican los internautas, las infracciones cometidas se toleran sin problemas y aún a veces, se incitan o al menos aplauden. Documentos Web, grupos de noticias, canales de IRC dedicados al intercambio, regalo o venta de productos piratas son muy populares, junto con los de ocio, donde cabe destacar los de contenido erótico. Decididamente, para la cultura informática el valor de la propiedad electrónica no es uno de sus pilares y se coloca por debajo de la libertad individual e implícitamente, de la responsabilidad personal.

Otros niveles de propiedad utilizados resaltan el sentido del humor que predomina en las relaciones por Internet. Así, términos como mailware, que obliga a los clientes del archivo a mandar un correo electrónico al propietario, o su 
versión postal, que proponía una dirección postal para mandar una carta con un sello sin usar dentro (seguramente para alimentar la filatelia del internauta), o bierware, que propone invitar a una cerveza al dueño del archivo.

\section{Referencias bibliográficas}

[TRE, 1996] Trejo Delarbe, R.: "La nueva alfombra mágica"; FUNDESCO, 1.996; Colección Impactos

[ESE, 1.996] Esebbag Benchimol, C. et al.: "Guía práctica para usuarios de Internet"; Anaya Multimedia, 1.996

[MCL, 1989] McLuhan, M. et al.: "La aldeal global";Editorial Gedisa, Colección El Mamífero Parlante, Barcelona, 1.993

[TER, 1.996] Terceiro, J. B.: "Socied@d digit@l", Alianza Editorial, Madrid, 1.996

[PIS, 1.995] Piscitelli, A.: "ciberculturas"; Paidos, Buenos Aires, 1.995

[JOY, 1.997] Joyanes, L. "Cibersociedad"; McGraw-Hill, Madrid, 1.997

[TUR, 1.995] Turkle, S.. "La vida en la pantalla"; Paidos, Barcelon, 1.995

[FUN, 1.994] Varios autores: "Apuntes de la sociedad interactiva"; FUNDESCO, 1.994; Colección Encuentros 